\title{
Change in quality of life: a follow up study among patients with HIV infection with and without TB in Ethiopia
}

\author{
Amare Deribew ${ }^{1 *}$, Kebede Deribe ${ }^{1}$, Ayalu A Reda ${ }^{2}$, Markos Tesfaye ${ }^{3}$, Yohannes Hailmichael ${ }^{4}$, Todd Maja ${ }^{5}$
} and Robert Colebunders ${ }^{6,7}$

\begin{abstract}
Background: There is a dearth of literature on the impact of TB/HIV co-infection on quality of life (QoL). We conducted a study to assess the change in QoL over a 6-months period and its predictors among HIV-infected patients with and without TB in Ethiopia.

Methods: 465 HIV-infected patients without TB and 124 TB/HIV co-infected patients were enrolled in a prospective study in February, 2009. 455 (98\%) HIV-infected and 97 (78\%) TB/HIV co-infected patients were followed for 6 months. Data on QoL at baseline and $6^{\text {th }}$ month were collected by trained nurses through face to face interviews using the short Amharic version of the World Health Organization Quality of Life Instrument for HIV clients (WHOQOL HIV-Brief). Common Mental Disorder (CMD) was assessed using a validated version of the Kessler-10 scale. Multivariate analysis was conducted using generalized estimating equations (GEE) using STATA to assess change in QoL and its predictors.

Results: There was a statistically significant improvement of the physical, psychological, social, environmental and spiritual QoL at the $6^{\text {th }}$ months follow up compared to the baseline for both groups of patients $(P<0.0001)$. The change in QoL in all dimension were more marked for TB/HIV co-infected patients compared to HIV-infected patients without TB.

A severe form of CMD was strongly associated with poorer physical QoL among TB/HIV co-infected individuals $(\beta=-2.84 ; P=0.000)$ and HIV clients without TB $(\beta=-2.34 ; P=0.000)$.

Conclusion: This study reveals that ART and anti-TB treatment significantly improve the QoL particularly among TB/HIV co-infected patients. We recommend that the ministry of health in collaboration with partners shall integrate mental health services into the TB/HIV programs and train health care providers to timely identify and treat CMD to improve QoL.
\end{abstract}

Keywords: TB/HIV co-infection, Quality of life, Antiretroviral treatment, Common mental disorders, Ethiopia

\section{Background}

The advent of anti-retroviral therapy (ART) and its widespread availability in many settings has reduced the mortality rate among people living with HIV/AIDS (PLHA) [1]. As longevity of PLHA improves as a result of ART, improvement of quality of life (QoL) of these patients has become an important issue for researchers and policy makers [2]. According to the World Health

\footnotetext{
* Correspondence: amare_deribew@yahoo.com

'Department of Epidemiology, Jimma University, Jimma, Ethiopia

Full list of author information is available at the end of the article
}

Organization (WHO), QoL is defined as an individuals' perception of their position in life in the context of the culture and value systems in which they live and in relation to their goals, expectations, standards and concerns [2]. This definition considers individuals' satisfaction on their physical, psychological, social relationships, environment, and spiritual aspects of their life [3].

In addition to its biological and physical burden, HIV/ AIDS is associated with many social consequences such as stigma and discrimination which have negative impacts on QoL [4-6]. QoL is also affected by several clinical and

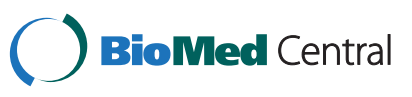

(c) 2013 Deribew et al.; licensee BioMed Central Ltd. This is an Open Access article distributed under the terms of the Creative Commons Attribution License (http://creativecommons.org/licenses/by/2.0), which permits unrestricted use, distribution, and reproduction in any medium, provided the original work is properly cited. 
Table 1 Socio-demographic and clinical characteristics of TB/HIV co-infected and HIV-infected patients without TB

\begin{tabular}{|c|c|c|c|}
\hline Variables & TB/HIV co-infected patients $(n=97)$ & HIV-infected patients without TB $(n=455)$ & P-Value \\
\hline Age in years, Mean (SD) & $34.5(9.5)$ & $33.4(8.1)$ & 0.2 \\
\hline \multicolumn{4}{|l|}{ Sex } \\
\hline Male & $43(44.3 \%)$ & $185(40.6 \%)$ & \multirow[t]{2}{*}{0.5} \\
\hline Female & $54(55.7 \%)$ & $270(59.4 \%)$ & \\
\hline \multicolumn{4}{|l|}{ Employment } \\
\hline Unemployed & $7(7.2 \%)$ & $52(11.4 \%)$ & \multirow[t]{2}{*}{0.2} \\
\hline Employed & $90(92.8 \%)$ & $403(88.6 \%)$ & \\
\hline \multicolumn{4}{|l|}{ Have income source } \\
\hline Yes & $69(71.1 \%)$ & $316(69.5 \%)$ & \multirow[t]{2}{*}{0.7} \\
\hline No & $28(28.9 \%)$ & $139(30.5 \%)$ & \\
\hline \multicolumn{4}{|l|}{ Have social support } \\
\hline Yes & $11(11.3 \%)$ & $63(13.8 \%)$ & \multirow[t]{2}{*}{0.5} \\
\hline No & $86(87.7 \%)$ & $392(86.2 \%)$ & \\
\hline \multicolumn{4}{|l|}{ WHO staging } \\
\hline Stage I & - & $71(15.6 \%)$ & \multirow[t]{4}{*}{0.000} \\
\hline Stage II & - & $64(14.1 \%)$ & \\
\hline Stage III & $79(81.4)$ & $216(47.5 \%)$ & \\
\hline Stage IV & $18(18.6 \%)$ & $65(14.2 \%)$ & \\
\hline Mean CD4 lymphocyte count, (median) & $392.6(375.0)(n=24)$ & $383.7(358.0)(n=160)$ & 0.8 \\
\hline Missed at least one dose of anti-TB treatment & $7(7.2 \%)$ & - & - \\
\hline Missed at least one dose of ART & $3(3.1)$ & $7(1.5 \%)$ & 0.535 \\
\hline Lost to follow-up & $27(21 \%)$ & $10(2.2 \%)$ & 0.000 \\
\hline
\end{tabular}

socio-demographic factors. In a prospective cohort study conducted in 2003 and 2004 among 947 HIV-infected adults initiating highly active antiretroviral therapy in Uganda, the overall score of QoL significantly increased from the baseline and most of the gains were achieved by the third month of therapy. While several clinical, psychosocial and socio-demographic factors predicted QOL at ART initiation, financial dependence on others was the only remaining predictor after controlling for time on ART [7]. Another cohort study among men in USA showed that higher family support and CD4 lymphocyte counts at baseline were predictive of improved changes in physical and social functioning over time, and higher depressive symptoms at baseline were predictor of diminished role functioning, emotional well-being, and general health perception [8]. Whereas a prospective cohort study conducted among 1053 patients in France revealed that baseline CD4 lymphocyte count, time since HIV diagnosis, undetectable viral load, and lower number of self-reported symptoms were predictors of QoL [9].

Other predictors of QoL include poor social support [10], depression $[6,10,11]$, unemployment [12] or financial dependence on others [6,7], older age [13] and being female [14].
Many studies have documented significant improvements in QoL during ART $[7,13,15]$. There is however a dearth of literature on the impact of tuberculosis (TB)/HIV co-infection on QoL. From February to April 2009, we conducted a QoL survey among HIV infected patients with and without TB in three hospitals in Ethiopia [6]. This study showed that TB/HIV co-infected patients had poorer QoL life than HIV infected patients without TB. In this paper, we describe the change in QoL of the same patients after 6-months of treatment.

Table 2 Change in QoL among TB/HIV co-infected patients after 6 months of treatment

\begin{tabular}{lcccc}
\hline QOL domain & $\begin{array}{c}\text { Mean (SD) } \\
\text { at baseline }\end{array}$ & $\begin{array}{c}\text { Mean (SD) } \\
\text { after } \mathbf{6} \\
\text { months }\end{array}$ & $\begin{array}{c}\text { Mean } \\
\text { difference } \\
\mathbf{( 9 5 \% ~ C l )}\end{array}$ & P-value \\
\hline Physical & $13.3(4.4)$ & $17.9(2.5)$ & $5.1(4.2-6.0)$ & 0.000 \\
Psychological & $15.0(3.2)$ & $17.9(1.8)$ & $3.3(2.6-4.0)$ & 0.000 \\
Level of independence & $11.7(3.7)$ & $17.0(2.4)$ & $5.7(4.9-6.6)$ & 0.000 \\
Social relationships & $12.2(3.7)$ & $14.5(2.5)$ & $2.6(1.7-3.5)$ & 0.000 \\
Environmental health & $11.6(3.1)$ & $14.2(2.7)$ & $2.8(2.1-3.6)$ & 0.000 \\
Spirituality health & $16.5(4.0)$ & $19.0(1.7)$ & $3.1(2.3-4.0)$ & 0.000 \\
\hline
\end{tabular}


Table 3 Change in QoL among HIV infected patients without TB after 6 months of treatment

\begin{tabular}{lcccc}
\hline QOL domain & $\begin{array}{c}\text { Mean (SD) } \\
\text { at baseline }\end{array}$ & $\begin{array}{c}\text { Mean (SD) } \\
\text { after 6 } \\
\text { months }\end{array}$ & $\begin{array}{c}\text { Mean } \\
\text { difference } \\
\mathbf{( 9 5 \% ~ C l )}\end{array}$ & P-value \\
\hline Physical & $16.8(2.8)$ & $17.5(2.5)$ & $0.7(0.4-1.1)$ & 0.000 \\
Psychological & $16.2(2.5)$ & $17.4(2.2)$ & $1.2(0.9-1.5)$ & 0.000 \\
Level of independence & $15.0(2.8)$ & $16.6(2.6)$ & $1.6(1.3-2.0)$ & 0.000 \\
Social relationships & $13.6(2.9)$ & $14.3(2.8)$ & $0.6(0.2-1.0)$ & 0.002 \\
Environmental health & $12.4(2.7)$ & $13.7(2.7)$ & $1.2(0.9-1.6)$ & 0.000 \\
Spiritual health & $17.9(2.9)$ & $18.5(2.3)$ & $0.7(0.4-1.0)$ & 0.000 \\
\hline
\end{tabular}

\section{Methods}

\section{Study settings and population}

From February to April 2009, 465 HIV-infected patients without TB and $124 \mathrm{~TB} / \mathrm{HIV}$ co-infected patients who were taking ART in three hospitals in Ethiopia were enrolled in a prospective study. The patient selection process was described in our previous paper [6]. In brief, at Jimma, Nekemte and Adama hospitals, for each TB/HIV co-infected patient, 3 HIV-infected patients without TB were selected using a simple random sampling technique. All TB/HIV co-infected patients were in the intensive phase of anti-TB treatment. Exclusion criteria for both groups included age less than 15 years, the presence of an opportunistic infection or a known chronic illness like diabetes mellitus and hypertension. Patients were followed up monthly.

\section{Data collection procedures and follow up}

Diagnoses of TB and HIV were based on national guidelines [16]. Smear microscopy was the major diagnostic tool for pulmonary TB. TB lymphadenitis was diagnosed based on clinical parameters and cytological examination of an aspirate obtained by fine needle aspiration. Patients with HIV infection were considered not to have TB if they did not present with any of the TB clinical symptoms [16]. During each clinic visit, patients were thoroughly assessed by trained nurses for drug side effects, general health status and presence of symptoms of opportunistic infection including TB. CD4 lymphocyte count and WHO clinical staging were extracted from the patients' record at baseline and at the $6^{\text {th }}$ months of follow up. QoL was measured at baseline and after 6 months of follow up through face to face interviews using the short Amharic version of the World Health Organization QoL Instrument for HIV infected patients (WHOQOL HIV-Brief) [17]. This QoL instrument has been described in our previous article [6]. In brief, it consisted of 31 Likert scale questions in 6 domains of QoL: Physical health (4 items); psychological wellbeing (5 items); social relationship (4 items); environmental health (8 items); level of independence (4 items) and spiritual health (4 items). There were two questions about general QoL and perceived general health.

Common Mental Disorder (CMD) was measured using the Kessler 10 scales [18]. This instrument has 10 questions each asking the respondent how often they experienced symptoms during the previous 30 days and containing 5 -point Likert scales $(1=$ never, $2=$ a small part of the time, $3=$ some of the time, $4=$ most of the times, $5=$ all of the time). The Kessler-10 scale was validated in Ethiopia and used extensively $[19,20]$.

\section{Data analysis}

Data were analyzed using the SPSS version 16.0 and STATA $^{\circledR}$ version 11 software. Domain scores in the WHOQOL-HIV-Brief were scaled in positive direction with higher score denoting good quality of life. Negative questions like pain and discomfort were recorded so that higher scores reflected better QoL. Mean scores of items within each domain were used to calculate the domain score. Mean scores were then multiplied by 4 in order to make domain scores comparable with the scores used in the World Health Organization QoL (WHOQOL-100). We used $\mathrm{t}$-test and F-test to compare means between groups.

QoL was treated as continuous variable. CMD was categorized as normal (score <20), moderate (score 20-24), severe (score 25-29) and very severe (score above 30) as proposed previously $[18,21]$. Paired T-test was used to compare repeated measurements of QoL at baseline and at 6 month. Multivariate analysis was conducted using generalized estimating equations (GEE) using the Gaussian family and the identity link function. In this model, the correlations between the baseline and 6-month measurements were taken into account. Variables with significant correlation were removed since the model

Table 4 Comparison of QoL among TB/HIV co-infected and HIV-infected patients without TB

\begin{tabular}{|c|c|c|c|c|}
\hline QOL domain & $\begin{array}{l}\text { Mean difference for } \\
\text { TB/HIV co-infected }\end{array}$ & $\begin{array}{l}\text { Mean Difference for } \\
\text { HIV-infected without TB }\end{array}$ & $\begin{array}{l}\text { Mean difference of } \\
\text { differences }(95 \% \mathrm{Cl})\end{array}$ & P-value \\
\hline Physical & $5.1(4.2-6.0)$ & $0.7(0.4-1.1)$ & $4.4(3.4-5.4)$ & 0.000 \\
\hline Psychological & $3.3(2.6-4.0)$ & $1.2(0.9-1.5)$ & $2.1(1.4-2.9)$ & 0.000 \\
\hline Level of independence & $5.7(4.9-6.6)$ & $1.6(1.3-2.0)$ & $4.1(3.2-5.0)$ & 0.000 \\
\hline Social relationships & $2.6(1.7-3.5)$ & $0.6(0.2-1.0)$ & $1.2(1.1-2.9)$ & 0.000 \\
\hline Environmental health & $2.8(2.1-3.6)$ & $1.2(0.9-1.6)$ & $1.6(0.8-2.4)$ & 0.000 \\
\hline Spiritual health & $3.1(2.3-4.0)$ & $0.7(0.4-1.0)$ & $2.4(1.5-3.3)$ & 0.000 \\
\hline
\end{tabular}


automatically detects correlations. A P-value of less or equal to 0.05 was taken as the cut-off value for statistical significance.

\section{Ethical clearance}

Ethical clearance was obtained from the Jimma University ethical review board. Written informed consent was obtained from the study participants. To ensure confidentiality, the data were anonymised before they were analyzed.

\section{Results}

After 6 months, 455 (98\%) of the 465 HIV-infected patients and $97(78 \%)$ of the $124 \mathrm{~TB} / \mathrm{HIV}$ co infected patients were still in follow up. Thirty seven $(6.3 \%)$ were lost to follow-up. There were no significant difference in baseline CD4 lymphocyte count between patients who completed the study and those lost to follow up, nonetheless most of the lost to follow-up were in WHO stage 3 and $4(\mathrm{P}=0.002)$.

Over the 6 months period, 5/455(1.1\%) patients with HIV infection developed pulmonary TB, 7 (7.2\%) of TB/ HIV co-infected patients and $10(1.8 \%)$ of all patients missed their anti-TB treatment and ART at least once. Twenty five percent of TB/HIV co-infected patients had their CD4 lymphocyte measured both at baseline and after 6 months, compared to 35\% of HIV infected patients without TB (Table 1).

\section{Change in quality of life}

In all patients, after 6 months of treatment there was a significant improvement of QoL in all its dimensions (physical, psychological, social relationships, environmental, spiritual and level of dependence) (Table 2 and 3).

The change in QoL in all its dimension was more pronounced for TB/HIV co-infected patients compared to HIV infected patients without TB. For instance, there was a 4.4 unit difference between TB/HIV co-infected and HIV infected patients without TB in the physical dimension of QoL (Table 4).

\section{Predictors of change in QoL}

Although not statistically significant, lack of social support, absence of a source of income and poor adherence to ART had a negative effect on the physical dimension of QoL of all patients. A severe form of CMD was strongly associated with poorer physical QoL among TB/HIV co-infected individuals $(\beta=-2.84 ; \mathrm{P}=0.000)$ and $\mathrm{HIV}$ infected patients without TB ( $\beta=-2.34 ; \mathrm{P}=0.000$ ) (Table 5).

Though not statistically significant, lack of social support had a negative effect on psychological QoL of TB/HIV co-infected patients $(\beta=-0.28, P=0.4)$ and HIV infected patients without TB $(\beta=-0.44, P=0.2)$. A severe form of CMD was strongly associated with poorer psychological QoL in both groups of patient (Table 6).
Table 5 Predictors of physical QoL among TB/HIV co-infected and HIV-infected patients without TB

\begin{tabular}{|c|c|c|c|c|}
\hline \multirow[b]{2}{*}{ Variables } & \multicolumn{2}{|c|}{ TB/HIV co-infected } & \multicolumn{2}{|c|}{ HIV-infected without TB } \\
\hline & $\beta$ (SE) & P-value & $\beta$ (SE) & P-value \\
\hline \multicolumn{5}{|l|}{ Sex } \\
\hline Male & 1.00 & & 1.00 & \\
\hline Female & $-0.26(0.4)$ & 0.5 & 0.07 & 0.7 \\
\hline \multicolumn{5}{|c|}{ Mean CD4 count } \\
\hline$<50$ & 1.00 & & 1.00 & \\
\hline $50-100$ & $0.98(0.8)$ & 0.2 & $0.13(0.3)$ & 0.7 \\
\hline $101-200$ & $0.28(0.8)$ & 0.7 & $0.17(0.28)$ & 0.5 \\
\hline$>200$ & $0.20(0.8)$ & 0.8 & $0.19(0.29)$ & 0.5 \\
\hline \multicolumn{5}{|c|}{ WHO staging } \\
\hline I & NA & & 1.00 & \\
\hline$\|$ & NA & & $-0.11(0.3)$ & 0.7 \\
\hline III & 1.00 & & $-0.28(0.3)$ & 0.3 \\
\hline VI & $-0.91(0.6)$ & 0.1 & $0.05(0.3)$ & 0.9 \\
\hline \multicolumn{5}{|c|}{ Adherence to ART } \\
\hline Yes & 1.00 & & 1.00 & \\
\hline No & $-0.61(1.2)$ & 0.6 & $-0.31(0.5)$ & 0.5 \\
\hline \multicolumn{5}{|c|}{ Adherence to anti-TB } \\
\hline Yes & 1.00 & & NA & \\
\hline No & $0.27(1.4)$ & 0.8 & & \\
\hline \multicolumn{5}{|c|}{ Social support } \\
\hline Yes & 1.00 & & 1.00 & \\
\hline No & $-0.27(0.5)$ & 0.6 & $0.11(0.3)$ & 0.7 \\
\hline \multicolumn{5}{|c|}{ Source of income } \\
\hline Yes & 1.00 & & 1.00 & \\
\hline No & $-0.49(0.6)$ & 0.4 & $-0.35(0.2)$ & 0.07 \\
\hline \multicolumn{5}{|l|}{ CMD } \\
\hline Normal & 1.00 & & 1.00 & \\
\hline Moderate & $-0.21(0.7)$ & 0.8 & $-0.69(0.2)$ & 0.001 \\
\hline High & $-0.88(0.6)$ & 0.2 & $-1.37(0.2)$ & 0.000 \\
\hline Very high & $-2.48(0.6)$ & 0.000 & $-2.34(0.3)$ & 0.000 \\
\hline \multicolumn{5}{|c|}{ Employment } \\
\hline Yes & 1.00 & & 1.00 & \\
\hline No & $0.42(0.7)$ & 0.6 & $-0.17(0.3)$ & 0.6 \\
\hline
\end{tabular}

*NA $=$ not applicable

\section{Discussion}

This study shows that all the dimensions of QoL have significantly improved after 6 months of treatment in both patient groups. However, the improvement in QoL was more pronounced for TB/HIV co-infected patients. The significant improvement of the physical quality of life of TB/HIV co-infected patients could be explained by the relief of TB symptoms during anti-TB treatment [22]. Some studies have documented that the major gain 
Table 6 Predictors of psychological QoL among TB/HIV co-infected and HIV-infected patients without TB

\begin{tabular}{|c|c|c|c|c|}
\hline \multirow[b]{2}{*}{ Variables } & \multicolumn{2}{|c|}{ TB/HIV co-infected } & \multicolumn{2}{|c|}{$\begin{array}{c}\text { HIV-infected patients } \\
\text { without TB }\end{array}$} \\
\hline & $\beta$ (SE) & P-value & $\beta$ (SE) & P-value \\
\hline \multicolumn{5}{|l|}{ Sex } \\
\hline Male & 1.00 & & 1.00 & \\
\hline Female & $-0.69(0.3)$ & 0.03 & $-0.22(0.2)$ & 0.1 \\
\hline \multicolumn{5}{|c|}{ Mean CD4 count } \\
\hline$<50$ & 1.00 & & 1.00 & \\
\hline $50-100$ & $1.15(0.6)$ & 0.06 & $-0.16(0.3)$ & 0.6 \\
\hline $101-200$ & $0.70(0.6)$ & 0.2 & $-0.12(0.2)$ & 0.6 \\
\hline$>200$ & $0.53(0.6)$ & 0.3 & $-0.01(0.2)$ & 0.969 \\
\hline \multicolumn{5}{|c|}{ WHO staging } \\
\hline | & & & 1.00 & \\
\hline$\|$ & & & $-0.36(0.3)$ & 0.2 \\
\hline III & 1.00 & & $-0.10(0.3)$ & 0.7 \\
\hline Vl & $-0.42(0.4)$ & 0.3 & $-0.04(0.3)$ & 0.9 \\
\hline \multicolumn{5}{|c|}{ Adherence to ART } \\
\hline Yes & 1.00 & & 1.00 & \\
\hline No & $0.06(0.8)$ & 0.9 & $0.40(0.5)$ & 0.4 \\
\hline \multicolumn{5}{|c|}{ Adherence to anti-TB } \\
\hline Yes & 1.00 & & NA & \\
\hline No & $0.43(1.0)$ & 0.7 & & \\
\hline \multicolumn{5}{|c|}{ Social support } \\
\hline Yes & 1.00 & & 1.00 & \\
\hline No & $-0.28(0.4)$ & 0.5 & $-0.44(0.2)$ & 0.06 \\
\hline \multicolumn{5}{|c|}{ Source of income } \\
\hline Yes & 1.00 & & 1.00 & \\
\hline No & $-0.06(0.4)$ & 0.9 & $-0.56(0.2)$ & 0.001 \\
\hline \multicolumn{5}{|l|}{ CMD } \\
\hline Normal & 1.00 & & 1.00 & \\
\hline Moderate & $-0.87(0.5)$ & 0.08 & $-0.51(0.2)$ & 0.010 \\
\hline High & $-0.76(0.4)$ & 0.09 & $-1.71(0.2)$ & 0.000 \\
\hline Very high & $-2.29(0.4)$ & 0.000 & $-2.04(0.3)$ & 0.000 \\
\hline \multicolumn{5}{|c|}{ Employment } \\
\hline yes & 1.00 & & 1.00 & \\
\hline No & $0.04(0.5)$ & 0.9 & -0.40 & 0.1 \\
\hline
\end{tabular}

in QoL among patients with HIV infection occurs in the first three months of initiating of ART $[8,23]$.

In our study, income and employment did not influence significantly QoL but this may be because of the small sample size of the study and most study participants had a similar socio-economic background. Indeed, other studies have shown that socio-economic status and social support are very important predictors of QoL of persons with HIV infection $[12,16]$. Gender also did not predict QoL in our study in contrast with some other studies that reported lower QoL among women $[14,24,25]$. This could be due to the presence of some income generating schemes by Civil Society Organizations targeting only HIV infected women in Ethiopia.

In contrast with other studies, we were unable to demonstrate that a lower CD4 lymphocyte count did not predicted a worse QoL [17]. This could be because of the small sample size of the study and secondly, all patients received adequate treatment with good adherence rate.

In our study, the presence of CMD was a main predictor of QoL after controlling other confounding variables. This suggests that screening and treatment of CMDs could be an important strategy towards improving the QoL of patients with TB and/or HIV in Ethiopia.

Our study has several limitations. First, the lost to follow up due to unknown reasons and missing data on CD4 count, particularly among TB/HIV co-infected patients, may have obscured the effect of CD4 lymphocyte count and WHO clinical staging on quality of life. Second, the cause-effect relationship between CMD and QoL could not be established. Third, we did not gather comprehensive information regarding income and occupation which might have impact on QoL.

\section{Conclusion}

Our study shows that ART and anti-TB treatment improves all dimensions of QoL. CMD is a major predictor of poor QoL. We recommend that the ministry of health in collaboration with partners shall integrate mental health services into the TB/HIV programs and train health care providers to timely identify and treat CMD to improve QoL.

\section{Competing interests}

The authors declare that they have no competing interests.

\begin{abstract}
Authors' contributions
AD conceived the study and was involved in the design, analysis and report writing. MT participated in the design and reviewed the article. AR analyzed the data and reviewed the article. YH was involved in report writing and reviewing. KD was involved in analysis and write up. TM has reviewed the article extensively. RC participated in the design and critically reviewed the
\end{abstract} article. All authors read and approved the final manuscript.

\section{Acknowledgement}

The authors acknowledge the HIV prevention and control office of the Oromiya regional health Bureau for funding the study. The authors appreciate the study participants for their cooperation in providing the necessary information.

\section{Author details}

'Department of Epidemiology, Jimma University, Jimma, Ethiopia. ${ }^{2}$ College of Public Health, Haromaya University, Alemaya, Ethiopia. ${ }^{3}$ Department of psychiatry, Jimma University, Jimma, Ethiopia. ${ }^{4}$ Department of Health Service management, Jimma University, Jimma, Ethiopia. ${ }^{5}$ Department of Health Studies, UNISA, PO Box 392, Pretoria, South Africa. ${ }^{6}$ Department of clinical Sciences, Institute of Tropical Medicine, Nationalestraat 155, Antwerp 2000, Belgium. ${ }^{7}$ Department of Epidemiology and Social Medicine, University of Antwerp, Campus Drie Eiken, Universiteitsplein 1, Antwerpen 2610, Belgium. 
Received: 21 December 2012 Accepted: 25 April 2013

Published: 29 April 2013

\section{References}

1. Sabin CA: The changing clinical epidemiology of AIDS in the highly active antiretroviral therapy era. AIDS 2002, 16(Suppl 4):S61-8.

2. Wu AW: Quality of life assessment comes of age in the era of highly active antiretroviral therapy. AIDS 2000, 14(10):1449-51.

3. WHO: Development of the World Health Organization WHOQOL-BREF quality of life assessment. The WHOQOL Group. Psychol Med 1998, 28:551-558.

4. Donohue MAT: The lived experiences of stigma in individuals with AIDS. A phenomenological investigation. NY: Doctoral dissertation, Adelphi University, Garden City; 1991.

5. Bunting SM: Sources of stigma associated with women with HIV. ANS AdV Nurs Sci 1996, 19(2):64-73.

6. Deribew A, Tesfaye M, Hailmichael Y, Negussu N, Daba S, Wogi A, Belachew T, Apers L, Colebunders R: Tuberculosis and HIV co-infection: its impact on quality of life. Health Qual Life Outcomes 2009, 7:105.

7. Stangl AL, Wamai N, Mermin J, Awor AC, Bunnell RE: Trends and predictors of quality of life among HIV-infected adults taking highly active antiretroviral therapy in rural Uganda. AIDS Care 2007, 19(5):626-36.

8. Jia H, Uphold CR, Wu S, Chen GJ, Duncan PW: Predictors of changes in health-related quality of life among men with HIV infection in the HAART era. AIDS Patient Care STDS 2005, 19(6):395-405.

9. Carrieri P, Spire B, Duran S, Katlama C, Peyramond D, François C, Chêne G, Lang JM, Moatti JP, Leport C, APROCO Study Group: Health-related quality of life after 1 year of highly active antiretroviral therapy. J Acquir Immune Defic Syndr 2003, 32(1):38-47.

10. Sarah A, Samar N, Huda Abu-Saad H, Jocelyn DeJong Jacques M: Quality of life in people living with HIV/AIDS in Lebanon. AIDS Care 2010, 22(6):687-696.

11. Vijairam S, Michael W. Ross, Bhaskaran Unnikrishnan \& Supriya Hegde: Association of quality of life with major depressive disorder among people with HIV in South India. AIDS Care 2012. doi:10.1080/09540121.2012.689809.

12. Rueda S, Raboud J, Mustard C, Bayoumi A, Lavis JN, Rourke SB: Employment status is associated with both physical and mental health quality of life in people living with HIV. AIDS Care 2011, 23(4):435-443.

13. Mannheimer SB, Matts J, Telzak E, Chesney M, Child C, Wu AW, Friedland G, Terry B: Community Programs for Clinical Research on AIDS. Quality of life in HIV-infected individuals receiving antiretroviral therapy is related to adherence. AIDS Care 2005, 17(1):10-22.

14. Mrus JM, Williams PL, Tsevat J, Cohn SE, Wu AW: Gender differences in health-related quality of life in patients with HIV/AIDS. Qual Life Res 2005, 14(2):479-91.

15. Casado A, Consiglio E, Podzamczer D, Badia X: Highly active antiretroviral treatment (HAART) and health-related quality of life in naive and pretreated HIV-infected patients. HIV Clin Trials 2001, 2(6):477-483.

16. Federal Ministry of Health Ethiopia: Guideline for the national TB Leprosy Control Programme in Ethiopia Addis Ababa, Ministry of Health. ; 2007.

17. O'Connel K, Skevington S, Saxena S: Preliminary development of the World Health Organization's Quality of Life HIV instrument (WHOQOL-HIV): analysis of the pilot version. Soc Sci Med 2003 57:1259-1275. doi:10.1016/S0277-9536(02)00506-3.

18. Kessler RC, Andrews G, Colpe LJ, Hiripi E, Mroczek DK, Normand SL, Walters EE, Zaslavsky AM: Short screening scales to monitor population prevalence and trends in non-specific psychological distress. Psychol Med 2002, 32:959-76. doi:10.1017/S0033291702006074.

19. Tesfaye M, Hanlon C, Wondimagegn D, Alem A: Detecting postnatal common mental disorders in Addis Ababa, Ethiopia: validation of the Edinburgh Postnatal Depression Scale and Kessler Scales. J Affect Disord 2010, 122(1-2):102-8.

20. Deribew A: The mental health consequences of intimate partner violence against women in Agaro Town, southwest Ethiopia. Trop Doct 2008, 38:228-229. doi:10.1258/td.2008.070353.

21. Andrews G, Slade T: Interpreting scores on the Kessler Psychological Distress Scale (k10). Aust N Z J Public Health 2001, 25:494-497.

22. Guo N, Marra F, Marra CA: Measuring health-related quality of life in tuberculosis: a systematic review. Health Qual Life Outcomes 2009, 7(14):1.

23. Jelsma J, Maclean E, Hughes J, Tinise X, Darder M: An investigation into the health-related quality of life of individuals living with HIV who are receiving HAART. AIDS Care 2005, 17(5):579-88.
24. Cederfjäll C, Langius-Eklöf A, Lidman K, Wredling R: Gender differences in perceived health-related quality of life among patients with HIV infection. AIDS Patient Care STDS 2001, 15(1):31-9.

25. Abboud S, Noureddine S, Huijer HA, DeJong J, Mokhbat J: Quality of life in people living with HIV/AIDS in Lebanon. AIDS Care 2010, 22(6):687-96.

\section{doi:10.1186/1471-2458-13-408}

Cite this article as: Deribew et al.: Change in quality of life: a follow up study among patients with HIV infection with and without TB in Ethiopia. BMC Public Health 2013 13:408.

\section{Submit your next manuscript to BioMed Central and take full advantage of:}

- Convenient online submission

- Thorough peer review

- No space constraints or color figure charges

- Immediate publication on acceptance

- Inclusion in PubMed, CAS, Scopus and Google Scholar

- Research which is freely available for redistribution

Submit your manuscript at www.biomedcentral.com/submit
C) Biomed Central 